\title{
English Language Proficiency Levels and Needs of International Postgraduate Students: Implications and Recommendations
}

\author{
Marlyna Maros ${ }^{1}$, Siti Hamin Stapa ${ }^{1} \&$ Mohamad Subakir Mohd Yasin ${ }^{1}$ \\ ${ }^{1}$ School of Language Studies and Linguistics, Faculty of Social Science and Humanities, Universiti Kebangsaan \\ Malaysia, Malaysia \\ Correspondence: Marlyna Maros, School of Language Studies and Linguistics, Faculty of Social Science and \\ Humanities, Universiti Kebangsaan Malaysia, Bangi, Malaysia. Tel: 60-3-8921-5000. E-mail: marlyna@ukm.my
}

Received: June 27, 2012 Accepted: July 19, 2012 Online Published: October 19, 2012

doi:10.5539/ass.v8n13p181 URL: http://dx.doi.org/10.5539/ass.v8n13p181

\begin{abstract}
The aim of this paper is to present the findings of a study on the language proficiency levels and needs among postgraduate students in Universiti Kebangsaan Malaysia (UKM), Malaysia to later develop a course suitable to the levels and needs of the students based on the findings. The study employed a self-report needs analysis questionnaire administered to newly enrolled 171 postgraduate international students. These students were largely from the middle-eastern countries aged between 22 to 45 years old from various disciplines. Data collected were analyzed quantitatively and findings were presented in the form of descriptive statistics. The findings revealed that majority of the students' proficiency levels were below the entry level of the university's requirement. Where else the results of needs analysis showed that the most crucial language skills needed by the students are listening and speaking. Based on the findings suggestions and recommendations are made to meet the needs of the international postgraduate students in the university.
\end{abstract}

Keywords: language proficiency, language testing, language needs, perception of language

\section{Background of Study}

At the time that this research was conducted the total number of population for international postgraduate students in UKM was close to 3000 . This number is expected to increase as UKM is one of the leading universities in many areas of research, hence attracting local and international students alike in its postgraduate programs. At the same time, the university encourages this development and has included internationalization of its academic programs and students enrollment. Since most of the research and programs were carried out with English as the medium of communication, learning, and publishing, the students need to be adequately equipped with proficiency in English. To be excellent in it will be a further advantage for both the students and UKM at large. For this purpose, their acceptance to the university is based on the score of the standardized English language Proficiency Test (TOEFL or IELTS). However, a large number of them were conditionally accepted without these scores, instead they are required to sit for a locally based exam, i.e., the English Proficiency and Placement Test (EPPT), which was designed by a team of experts in language testing in UKM. The test consists of evaluation of the four proficiency skills which are: listening, speaking, reading, and writing. The accumulated scores were given in sets of bands, between band 1 (lowest) to band 5 (highest). Students scoring bands 1 and 2 are then required to enroll in the English Language Proficiency Course (MKBI, it's more popular Malay acronym for 'Modul Kemahiran Bahasa Bahasa Inggeris') for one semester. The course consists of 3 modules, namely; Academic Reading, Academic Writing, and (Academic) Oral Communication which includes the teaching of the skill of listening and intercultural communication as well. For more than five semesters this course had run based on modules that are designed as a general, academically-oriented English proficiency classes. As the enrollment of international postgraduate students is on the rise, the researchers who are part of the teams of both EPPT and the MKBI at various periods of their implementations, feel that there should be an attempt to study the modules provided for this proficiency course. The reason is, the course is now running based solely on the result of the students' EPPT exam, leaving a void in the needs adequacy of the course, which can only be obtained via research. Hence the aim of this research, that is, to inter-relate UKM's international postgraduate students' language proficiency and needs, to then recommend a course which is based on these levels and needs. The findings would be significant to gauge the syllabus for the current English proficiency 
course for international students at UKM with respect to the empirically confirmed language needs of the students while at the same time would help to develop suggestions for future running of the course. The findings could also benefit other universities within the same level of international development and those planning to internationalize their programs.

According to Hyland (2006), needs analysis is a key feature in the academic courses. Currently, needs analysis "has become a form of educational technology represented in a range of research methodologies that can be applied before, during or after language courses" (Hyland, 2003b). According to Benesch (2001), needs analysis in English for Academic Purpose (EAP) consists of gathering data about the target situation as the basis for designing EAP courses and materials.

West (1994) believes that the concept of needs has never been clearly defined. However, needs has been interpreted in different ways. Hutchinson and Waters (1987) offer a useful classification of needs into "necessities", "lack" and "wants". By necessities they mean what the learner has to know in order to function effectively in the target situation. "Lacks" for them represent the gaps between the target proficiency and what the learner already knows. Finally, they see "wants" as the subjective needs of learners.

As far as language needs is concerned, the findings have been related to language needs in improving classroom tasks. Many studies have been conducted based on needs in the classroom setting but have not investigated ESL/EFL students' language needs in a larger context. Zhu and Flaitz (2005), observed that students' academic experience encompasses their experience outside of the classroom in the institutional setting as well, and that students' classroom performance can be influenced by their interactions with people in the larger institutional context. Thus, it is deemed necessary to investigate the needs of the students when it comes to the types of skills required outside the classroom, and this experience can be transformed into the types of activities in the classroom.

Vifansi (2002) conducted a study which focuses on academic writing needs at a community college in Columbia. The study aimed at determining the academic writing needs of ESL students and delineating between the target needs and learning needs. Data was collected through focus group interview with 25 students attending a writing course. The results of the analysis and categorization of data uncovered that ESL students articulated both target needs and learning needs. The target needs involved the skills expected at the end of the course and usually stated as writing course's goals, whereas, the learning needs expressed students' difficulties to attain the goals of course. The study concluded that along with the target needs, ESL students learning needs also to be considered.

In Malaysia a recent study was carried out by Momtazur Rahman et al (2009). The objective of the study was to propose an ESP writing course for foreign postgraduate students in Universiti Kebangsaan Malaysia. The findings of the study suggest that the students need a number of important writing tasks and skills in writing theses, project papers and assignment.

Bacha (2003) conducted a study to compare the faculty's and the students' perceptions of an English for Academic Purposes (EAP) and English for Professional Purposes (EPP). The findings revealed that the English courses offered need to focus both the academic tasks as well as issues relating to job activities needed after graduation.

Bacha and Bahous (2008) carried out needs analysis survey to investigate the writing needs and language proficiency levels of students majoring in business at the Lebanese American University. The findings show that the students perceived their writing skills as more satisfactory than the instructors perception, differed on what writing tasks that were necessary in their course, but agreed that both the business and English instructors should cooperate in the teaching of English.

One recent study was carried out by Al-Tamimi and Munir Shuib (2010) aimed at identifying five issues: the students' perceptions of the frequency of English language skills used, the importance of these skills, their ability in performing the skills, the areas of language use that they need training/teaching in and their preferences for English language course. The major findings demonstrated that the participants considered all language skills to be important, they felt that they cannot use English effectively and that the English course does not meet their needs. The study concluded with recommendations for improving the teaching of English for petroleum and engineering students. Meanwhile, Assagaf (2010) surveyed the needs of tertiary level students in a private university in Yemen to investigate the writing needs of a group of students registered for a technical writing course.

All of these studies mentioned above indicated that it is important for any English language proficiency program to take into account the institutional and also the students' needs in order to create programs that are meaningful 
to the students and to ensure that they are managed in efficacious manner.

\section{Objectives of Study}

To guide the direction of the research and attaining the results to commend future decisions for the program, it is worth while here to state the objectives of the study, which are to:

1) investigate the foreign postgraduate students' level of English language proficiency,

2) identify the perception of the importance of learning English among the foreign postgraduate students,

3) identify the language needs of the foreign postgraduate students, and

4) recommend English language courses based on the levels and needs of the students.

\section{Research Methodology}

In order to ascertain empirical significance, the study employed a quantitative research design where a set of self-report questionnaire was administered to a group of international postgraduate students in UKM. They were 171 UKM foreign postgraduate students' enrolled in the first semester of 2010/2011 and in the age group of $22-$ 45 years old. The majority of them were males $(61.4 \%)$, while females consisted of $38.6 \%$. They came from various regions like the Middle East countries like Iran, Iran and Libya (80.1\%), Southeast Asian countries like Indonesia, Thailand and Brunei (15.1\%), and other countries like Nigeria, China, and Bangladesh (4.8\%). Most of the respondents were studying in the Engineering faculty (26.5\%), Sciences (24.1\%), Social Sciences (25.3\%), Technology and Information Sciences (17.9\%), and others (6.2\%).

The instruments used were: a Self-Report Questionnaire consisting of proficiency/general background questions such as age, gender, country of origins, and faculties; and Needs analysis based on the Likert scale consisting of questions relating to the subjects' perceptions on the importance of learning English and the problems they encountered in learning English in UKM.

\section{Research Procedures}

The following steps were taken when conducting this study. First, a group of 171 new first semester foreign post-graduate students registered for the year 2010/2011 session were identified through a required Bahasa Melayu (Malay language) class. The questionnaires were administered through the cooperation of the lecturers teaching the course. The construction of the questionnaire was based on the objectives of the study. This questionnaire was pilot-tested to a group of 10 post-graduate international students as the researchers wanted to make sure that similar respondents understood the items on the questionnaire. This pilot study revealed that a few students faced some difficulties in understanding a few items, either because they were vague or confusing. These items were improved or deleted altogether before the final set of questions was administered to the actual respondents.

\section{Findings and Discussion}

Based on the information collected from the participants, the results were analyzed by the researchers and will be presented here based on the research objectives mentioned earlier.

1) The first research objective of this study is to investigate the foreign postgraduate students' level ofEnglish language proficiency. The proficiency levels of the students were determined by the results of the English Language Proficiency and Placement Test (EPPT). This internal UKM test was designed to gauge the level of English language proficiency among the incoming foreign students. These new students have the option of taking either IELTS or TOEFL beforehand in lieu of sitting for EPPT when they arrived in UKM before being allowed to proceed their studies. Table 1 below shows the EPPT results for the international students from 2009 $-2011$.

Table 1. EPPT results 2009-2011

\begin{tabular}{lcccc}
\hline Year & & $2009 / 2010$ & & $2010 / 2011$ \\
\hline Semester & I & II & I & II \\
Band 5 & 3 & 6 & 4 & 0 \\
4 & 1 & 20 & 8 & 6 \\
3 & 51 & 56 & 25 & 16 \\
$2^{*}$ & 77 & 112 & 73 & 50
\end{tabular}


$1 *$

TOTAL
37

169
41

235
25

135
8

80

*Required to take MKBI classes

From 2009 - 2011, a total of 619 students took the EPPT but only 196 (31.7\%) passed this test by getting Band 3 or better. This means that almost $70 \%$ of the students registered during these sessions were considered to have not met the minimum level of English language proficiency to cope with the demands of their academic survival. The EPPT follows the following bands and scores to categorize the students:

Table 2. EPPT scores and bands

\begin{tabular}{ccccc}
\hline Band 1 & Band 2 & Band 3 & Band 4 & Band 5 \\
\hline$(0-44)$ & $(45-64)$ & $(65-74)$ & $(75-84)$ & $(85-100)$ \\
\hline
\end{tabular}

Table 3. EPPT and MKBI band description

\begin{tabular}{|c|c|c|}
\hline BAND & USER & DESCRIPTORS \\
\hline 5 & Very good & $\begin{array}{l}\text { - } \quad \text { Expresses ideas and opinions with very high level of fluency, accuracy and } \\
\text { confidence in Speaking and Writing } \\
\text { - } \quad \text { Shows very high level of comprehension of written and spoken texts } \\
\text { - } \quad \text { Displays very high level of critical thinking abilities }\end{array}$ \\
\hline 4 & Good & $\begin{array}{l}\text { - Expresses ideas and opinions with high level of fluency, accuracy and confidence } \\
\text { in Speaking and Writing } \\
\text { - } \quad \text { Shows high level of comprehension of written and spoken texts } \\
\text { - } \quad \text { Displays high level of critical thinking abilities }\end{array}$ \\
\hline 3 & Competent & $\begin{array}{l}\text { - Expresses ideas and opinions with adequate level of fluency, accuracy and } \\
\text { confidence in Speaking and Writing } \\
\text { - Shows adequate level of comprehension of written and spoken texts } \\
\text { - Displays adequate level of critical thinking abilities }\end{array}$ \\
\hline 2 & Limited & $\begin{array}{l}\text { - Expresses ideas and opinions with low level of fluency, accuracy and confidence } \\
\text { in Speaking and Writing } \\
\text { - } \quad \text { Shows low level of comprehension of written and spoken texts } \\
\text { - } \quad \text { Displays low level of critical thinking abilities }\end{array}$ \\
\hline 1 & Very limited & $\begin{array}{l}\text { - Incapable of expressing ideas and opinions in Speaking and Writing } \\
\text { - Unable to comprehend written and spoken texts } \\
\text { - } \quad \text { Lacks critical thinking abilities }\end{array}$ \\
\hline
\end{tabular}

In UKM, those students who did not manage to get the minimum required band in EPPT (Band 3) are rquired to take a remedial course known as the English Language Proficiency Modul (MKBI). This module consists of 3 seperate courses dealing with the different language skills, namely oral communication, academic reading, and academic writing. The MKBI is ran for 14 weeks with a minimum contact hours of 12 per week. At the end of the course, the students are tested and given bands which correspond to the ones used for EPPT. Consequently, only students who scored band 3 and above are allowed to continue with the normal courses as required for their disciplines.

If we looked at the performance of the students who were required to do MKBI for the same period (2009 to 2011), it can be seen that the majority of them managed to pass the courses with Band 3 or better $(71.7 \%$ in $2009 / 2010$ session and $80.3 \%$ in 2010/2011 session). Based on their performance these students were deemed to be competent users of the language and were allowed to proceed in their studies.

Table 4. MKBI results 2009-2011

\begin{tabular}{lcccc}
\hline Year & \multicolumn{2}{c}{$2009 / 2010$} & \multicolumn{2}{c}{$2010 / 2011$} \\
\hline Semester & I & II & I & II \\
Group 1 - Passed all subjects with Band 3 or better & 71 & 81 & 60 & 42
\end{tabular}


Group 2 - Passed 1 or 2 subjects with Band 3 or better

$\begin{array}{cccc}20 & 30 & 12 & 8 \\ 7 & 3 & 3 & 2 \\ 98 & 114 & 75 & 52\end{array}$

Group 3 - Failed all subjects

TOTAL

The actual performance of these students was quite different from the self-assessment they were required to
answer as a part of the questionnaire. Here the majority of them rated themselves as having a good command of English where as their actual performance indicated otherwise.

2) The second objective of this research is to identify the perception of the importance of learning English among the foreign postgraduate students. There were questions in the survey dedicated to the positive and negative importance of the language as perceived by the respondents.

Table 5. The positive importance of learning English

\begin{tabular}{lccc}
\hline Reason & N & Mean & SD \\
\hline Useful & 171 & 3.62 & 0.670 \\
Talk to Malaysians and others & 171 & 3.43 & 0.719 \\
Get more respect in society & 171 & 3.06 & 0.805 \\
Widen thinking & 169 & 3.15 & 0.655 \\
Optional subject in UKM & 163 & 2.40 & 0.900 \\
Compulsory subject in UKM & 164 & 2.73 & 0.941 \\
Should be interested in learning English & 169 & 3.27 & 0.670 \\
Passport to learning abroad & 165 & 3.25 & 0.744 \\
Widen social circles & 160 & 3.14 & 0.759 \\
\hline Table 6. The negative importance of learning English & & & \\
\hline Reason & $\mathrm{N}$ & Mean \\
\hline Not needed in Malaysia & 170 & 1.62 & .883 \\
Difficult to learn & 168 & 2.27 & .822 \\
Classes not interesting & 167 & 1.92 & .824 \\
Waste of time in UKM & 165 & 2.09 & .968 \\
Not important subject in UKM & 171 & 1.80 & .900 \\
Makes no difference to life & 170 & 1.84 & .940 \\
\hline
\end{tabular}

From the tables above, it is clear that the respondents perceived that English is an important subject to be mastered/learned in UKM.

3) The third objective of the study is to identify the language needs of these foreign post-graduate students. To achieve this, the research employed a quantitative approach by administering a set of needs analysis questionnaire described in section 4.2.1. For the purpose of this discussion the results will be presented according to the different categories. The first category is the reasons for learning English. Table 7below reveals that the respondents had the following needs to learn and acquire English.

Table 7. Needs to learn English

\begin{tabular}{lccc}
\hline Need & $\mathrm{N}$ & Mean & SD \\
\hline 1. Read and refer to books and journals & 171 & 3.45 & 0.721 \\
2. Write assignments and articles & 170 & 3.49 & 0.608 \\
3. Speak effectively to lecturers, UKM officers and friends & 171 & 3.53 & 0.607 \\
4. Listen effectively to lecturers, UKM officers, friends, in seminars and conferences, & 171 & 3.53 & 0.607 \\
etc. & & & \\
5. Internet usage & 170 & 3.39 & 0.698 \\
6. Able to get good jobs easily & 170 & 3.15 & 0.705 \\
\hline
\end{tabular}


The next category is the list of items the researchers considered as problematic to the students because they are in English. For example, Table 8below shows that 36.3\% agreed that it is a problem for them to understand lectures and tutorials, $38.3 \%$ agreed that they had problems making appointments with officials outside UKM, $37.9 \%$ agreed that they had problems making oral presentations in seminars and conferences, and $36.8 \%$ indicated that they had problems in interacting effectively for daily activities inside/outside UKM. However, half of the respondents claimed that they did not encounter problems in the following activities: reading course materials, lecture notes, and references books; writing down lecture notes, writing emails to lectures, etc, answering exam questions, and lastly, participating in classroom and group discussions. These were not problematic to them as the survey revealed. The students' self-assessment of their own abilities to function effectively and appropriately in English do not match with their actual performance in both EPPT and MKBI as Tables 3 and 4 above showed.

Table 8 . Problems faced by students

\begin{tabular}{lcc}
\hline Problems & $\mathrm{N}$ & Percentage who agreed \\
\hline Understanding lectures and tutorials & 171 & 36.3 \\
Making appointments with UKM staff & 169 & 33.7 \\
Making appointment with outside UKM officials & 167 & 38.3 \\
Making oral presentations in seminars and conferences & 169 & 37.9 \\
Interacting effectively for daily activities inside/outside UKM & 171 & 36.8 \\
\hline
\end{tabular}

The table above also showed that the top 3 of 5 problems that they faced are not related to academic at all. Activities like "making appointment with UKM officials and outsiders" and "interacting effectively for daily activities" are non-academic activities. This is an example of how the needs of the students did not match with their own self-assessment.

4) The fourth objective of this study is to recommend English language courses based on the levels and needs of the students. The study reveals that there are several important issues that need to be addressed for the improvement of English language teaching and learning for the post-graduate students in UKM. First, finding from the research objective one suggests students have not met the minimum English languge requirement set by the university. Hence there is a real need for them to take English language course in UKM to bring them up to par. Similarly, research objective two shows that the students themselves perceived the importance of learning the language. Research object three suggests the areas that need to be addressed as the major components of an English language course offers by UKM. The survey shows that there is a need to focus on the oral component of the English course. This oral component should include:

- Speaking and listening effectively to lecturers, other university/public officials inside and outside UKM. This can be addressed through the emphasis on activities like simulations (for example, drama and role play) and an impromptu public speaking.

- Planning and the actual academic presentation activities like brainstorming, researching for materials, fine tuning research topic, rehearsing and editing, and how to handle questions from the audience.

- Interacting effectively for daily activities inside and outside UKM. Tasks may include group discussion for various daily conversational topics, politeness strategies, making appointments, and handling cultural differences.

The second recommendation is on the reading component of the English course. The aspects that need to be focused in the reading component should include academic reading skills for books, journals, online materials, and etc. Finally, the writing component also needs to be addressed. The skills needed as identified by the participants include writing assignments and articles. Some of the activities that can be included are all the three stages (prewriting, writing, and revising) in the academic writing process.

\section{Discussion and Conclusion}

Apart from the above recommendations that are formal or classroom-based activities, we would also like to suggest the followings:

- Writing clinic where students can bring their written drafts (of research proposals, assignments, projects, etc) to be commented by the professional advisors/editors/language specialists. 
- Language enhancement programs such as International English Language Week where students can be involved in activities such drama/plays, debate, public speaking, forums, community involvement with local English-based educational institutions.

- Pre-sessional language and culture program where students will be introduced to foundation English in all four skills (reading, writing, speaking, listening) and knowledge on Malaysian academic culture.

There are a few important points that can be drawn from this study, but the most important is the fact that there are many discrepancies between the students' perceptions and their actual competency in the English language. It has been shown that even though the students think highly of their ability to cope with the appropriate levels of English language needed to successfully completed their study in UKM, the actually performance indicated otherwise. Hence there are also mismatches between what they perceived as their immediate needs and the actual needs based on their performance/ability. It seems that the most important skills needed are actually listening and speaking while writing seemed secondary. This study has recommended a few important ways of how to overcome this problem. It is necessary for the university administrators and teaching staff to realize that courses designed must be dynamic, requiring constant re-examination from everyone involved and most importantly, they must meet the needs of the students.

\section{References}

Al-Tamimi, A. S., \& Shuib, M. (2010). Investigating the English language needs of petroleum engineering students at Hadhramout University of Science and Technology. Asian ESP Journal, 6(1), 1-30.

Assagaf, H. T. (2010). L2 writing in ESP context: investigating the current practices and needs at a tertiary institution in Yemen. Unpublished PhD Thesis. Universiti Kebangsaan Malaysia.

Bacha, N. (2003). English across academic and professional communities: a study of EFL learners' need at the Lebanese American University. AAICU Journal, 2.

Bacha, N., \& Bahous, R (2008). Contrasting views of business students' writing needs in EFL environment. English for Specific Purposes, 27, 74-93. http://dx.doi.org/10.1016/j.esp.2007.05.001

Benesch, S. (2001). Critical English for academic purposes: theory, politics and practice. London: Lawrence Erlbaum Associates.

Hutchinson, T., \& Waters, A. (1987). English for specific purposes: a learning-centered approach. Cambridge: CUP. http://dx.doi.org/10.1017/CBO9780511733031

Hyland, K. (2003b). Second language writing. London: Pearson Education. http://dx.doi.org/10.1017/CBO9780511667251

Hyland, K. (2006). English for academic writing: an advanced resource book. New York: Routledge.

Momtazur, R. M., Thang, S. M., Mohd, S. A. A., \& Norizan, A. R. (2009). Needs analysis for developing an ESP course for foreign postgraduates in science and technology. Asian ESP Journal, 5(2), 34-59.

Vifansi, E. (2002). Academic writing needs: an exploratory study of writing needs of ESL students. Ph.D thesis. Purdue University.

West, R. (1994). Needs analysis in language teaching. Language Learning, 27, 1-19.

Zhu, W., \& Flaitz, E. (2005). Faculty views on the importance of writing, the nature of academic writing and responding to writing in the disciplines. Journal of Second Language Writing, 13, 39-48. 